\title{
Urban storm-water special planning method based on the theory of a "storm-water management unit"
}

\author{
T. Wang \\ School of Architecture and Urban Planning \\ Huazhong University of Science and Technology, China
}

\begin{abstract}
Recently, urban waterlogging issue has become a big challenge for the sustainable development of a city and the method of urban planning and design. As a basis to the knowledge of LID (low impact development) theory and water supply and sewerage planning, this article investigates the reasons for urban waterlogging deeply, puts forward the concept of a "storm-water management unit" and its corresponding theory, and summarizes the methods of urban stormwater special planning as follows: 1) Environmental carrying capacity assessment in storm-water; 2) Estimation of total quantity of the urban rainfall runoff; 3) Establish the target of the storm-water drainage; 4) Divide the "stormwater management unit"; 5) Set the control index of storm-water drainage; 6) Choose the LID practices. The method of storm-water special planning will establish a theoretical foundation for the sustainable development of the city. Keywords: storm-water management unit, urban planning, storm-water special planning.
\end{abstract}

\section{Introduction}

Urban waterlogging in China is becoming frequent and, the reason is that, simply, there is not time enough to drain the gathering storm-water runoff on the ground after the rain. From the point of urban development, there are quite a lot of origins of urban waterlogging, which involves an administrative system, the methodology of urban planning, construction quality, maintenance and management of the municipal drainage pipeline and effectiveness of the industry regulations. However, these are not the direct reasons for directly leading to the 
urban waterlogging. We can find out from the China's urbanization process that the urban morphology evolution (especially city underlying surface morphology evolution) has close relationships with the urban waterlogging. Otherwise, the poor technology and capability of storing and draining the storm-water runoff also make the urban waterlogging more possible, which is the direct incentive.

\subsection{The area of the permeable ground shrink because of the overdevelopment of the cities leading to the surge of storm-water runoff}

With the speeding up of China's urbanization process and the surge of urban population, urban development intensity turns to be on the rise, and every parcel would be constructed with the highest building density and volume rate. On the other side, the increase of the development density is also reflected in the surge of the pavement area and underground parking area, which leads to the shrinkage of the natural permeable ground area, the bigger integrated runoff coefficient and the more storm-water runoff quantity.

\subsection{The backward drainage system and drainage technology}

The minor system is often used in the cities of China when building the drainage system. It shows a process of the gathering of the rainwater from the ground to the branch drainage pipeline, and then to the urban main drainage pipeline. Rainwater in the main pipeline will be drained into the natural water system by pump or in other ways at last. This minor system is mainly suitable for the regular rainfall or 1-in-2-10-years rain and the rainwater is drained by regular pipeline system. However, when the storm-water heavier than 1-in-10 years comes, these backward drainage systems will not satisfy the drain. Otherwise, LID IMPs (Low Impact Development Integrated Management Practices) like green roof, green road, bio-retention and pervious pavement are seldom utilized in Chinese cities, which adversely affects the lands' ability to store the rainwater and to avoid the storm-water peak and the storm-water runoff would take quite a short time to splash into the pipeline directly. As a result, the drainage system broke down under the excessive loads.

\subsection{The drain time extend because of the expansion of the built-up area}

As the expanding of the built-up area in the city, the length of the municipal drainage pipelines increases rapidly, to some extent, which drain the rainfall to the natural water system for more time. Secondly, the longer the pipeline is, the higher drain resistance it has. So short pipelines will take much less time to drain than the long pipelines, from which the time length between them is the one for urban waterlogging. During the urban development, overlong pipeline layout will have a strong impact on the drainage capability and lead to higher urban waterlogging possibility (figs 1 and 2). 


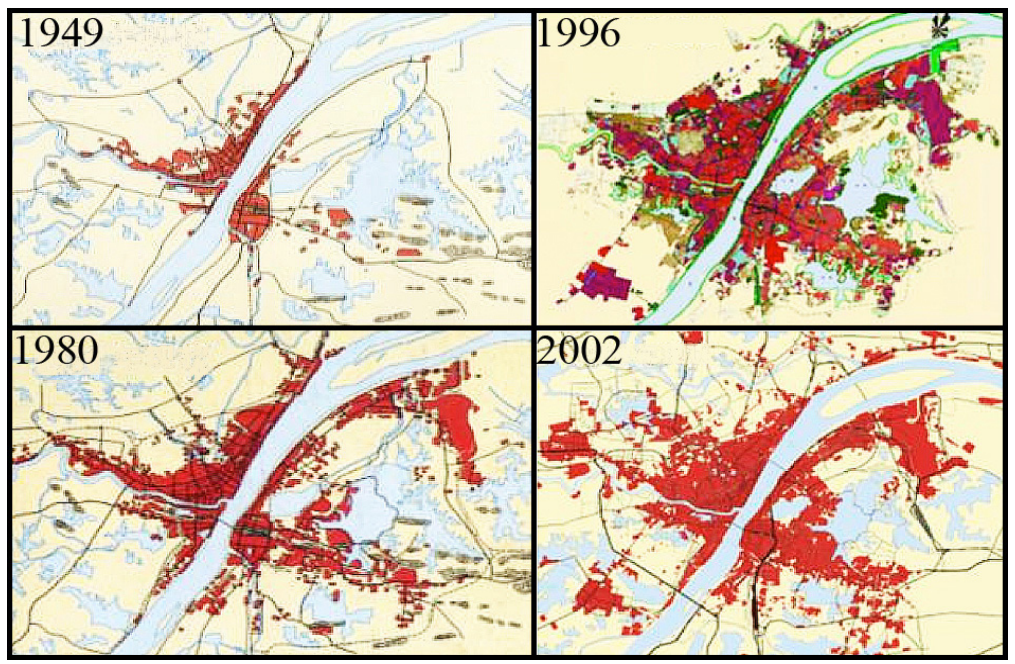

Figure 1: The progress of the built-up area's extension, Wuhan.

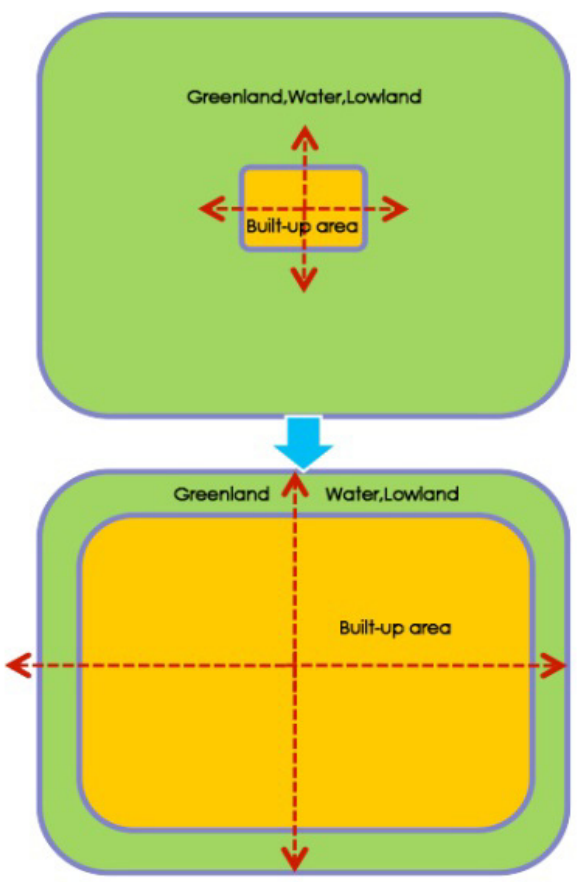

Figure 2: $\quad$ The diagram of the built-up area's extension. 


\subsection{Shrinkage of the urban water and lake system caused by urban development decreases the adjustment ability}

Because of an imperfect legal regime and other reasons, developers in China sometimes landfill lakes and water areas to get more development land, which leads to the continual water system shrinkage and the urban water and lake system losing the capacity to store and drain the storm-water runoff. Take the Wuhan city named by "1000 lakes city" as an example, there were over 127 lakes in the city in 1950 s while this number descend to 38 nowadays, and the lake area turns from $1581 \mathrm{~km}^{2}$ down to $847 \mathrm{~km}^{2}$ in $1980 \mathrm{~s}$ and it kept descending during the past 30 years. Till now only $61 \%$ water areas had been left from 1991 to 2010 [1] (fig. 3).
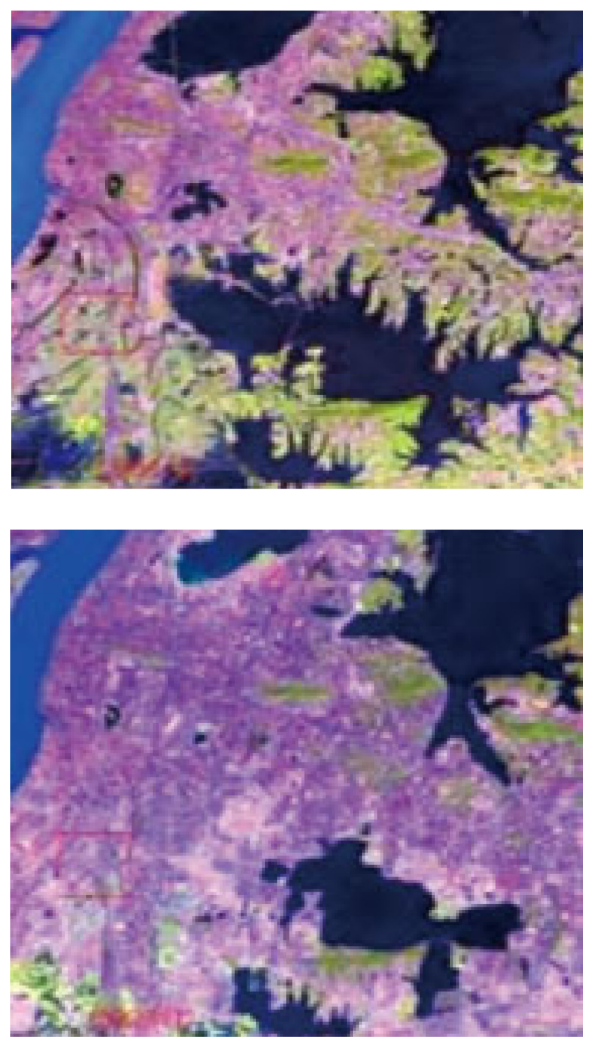

Figure 3: The extension of the lakes since 1980s, Wuhan.

\section{The theory of the "Storm-water Management Unit (SMU)"}

Based on the theory of Low Impact Development, the best way to manage the storm-water is to control the source of the storm-water. Reflecting on the drainage systems situation in China, the catchment area divided by the urban 
main road determines the extended distance of storm-water pipe, which leads to the following situation: When the pipe can't discharge all storm-water, waterlogging depends on whether the storm-water can branch into the trunk in time, In other words, the storage capability of storm-water pipe depends on the length of the branch pipe, if the branch pipe is too long to discharge the excessive storm-water, the perched water will appear on the ground. From this perspective, a large catchment area determines a long branch pipe, a long branch pipe delay the best chance to discharge storm-water, which is the main cause of the waterlogging. Based on the above points, the concept of "catchment area" in drainage planning is not quite reasonable. So, how to plan a reasonable "catchment area" is a theoretical direction of "Storm-water Management Unit".

\subsection{The concept of "storm-water management unit" and the model}

"Storm-water Management Unit" is a space unit, which, according to control the index of the land development intensity, targets at minimizing the stormwater runoff to realize the quantitative control to the storm-water drainage. The indexes include the building density, the greening rate, the natural-infiltrationland area rate, the roof-greening rate, pavement infiltration rate, etc. The stormwater management unit model is as follows (fig. 4).

\subsection{The "storm-water management unit" theory}

\subsubsection{The boundary of SMU - storm-water quantitative management area (SQMA)}

In the process of the urban master planning, the land layout needs to be in harmony with the hydrologic cycle. Based on the analysis of urban hydrology environment, we need to delimit the conservation area of the green space (green line) and the river and lake system (blue line), determine the principle for protecting the coastline, and also delimit the flood submerged area, the water environment and ecological sensitive area, the soil erosion sensitive area, floodplains area, etc. In addition to these areas, the left area, so called the StormWater Quantitative Management Area, needs to be quantitatively controlled, which is similar to the scope of a "banning construction area" and the "ecological security pattern". The difference between them is that the boundary of SMU delimited by hydrology index, while the evaluation index of "banning construction area" and "ecological security pattern" is relatively complex.

\subsubsection{The principle of "storm-water management unit"}

The principle is as follows: Firstly, we define the area of SQMA as $S_{\max }$ and set the area of SMU as $\mathrm{S}_{\text {unit }}$; Secondly, according to the water environment carrying capacity assessment, we can calculate the maximum of runoff quantity in SQMA as $Q_{\max }$. So, if we assume there is the uniform rainfall in SQMA, the maximum of runoff quantity in $\mathrm{SMU}\left(\mathrm{Q}_{\text {unit }}\right)$ can be calculated by the following formula:

$$
\mathrm{Q}_{\text {unit }}=\frac{\text { QmaxSunit }}{\text { Smax }}
$$




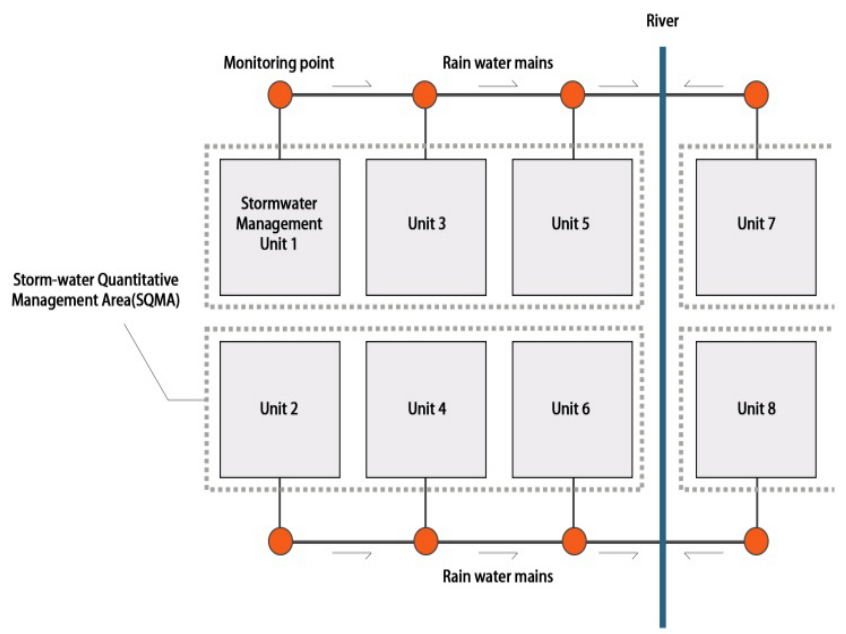

(a)

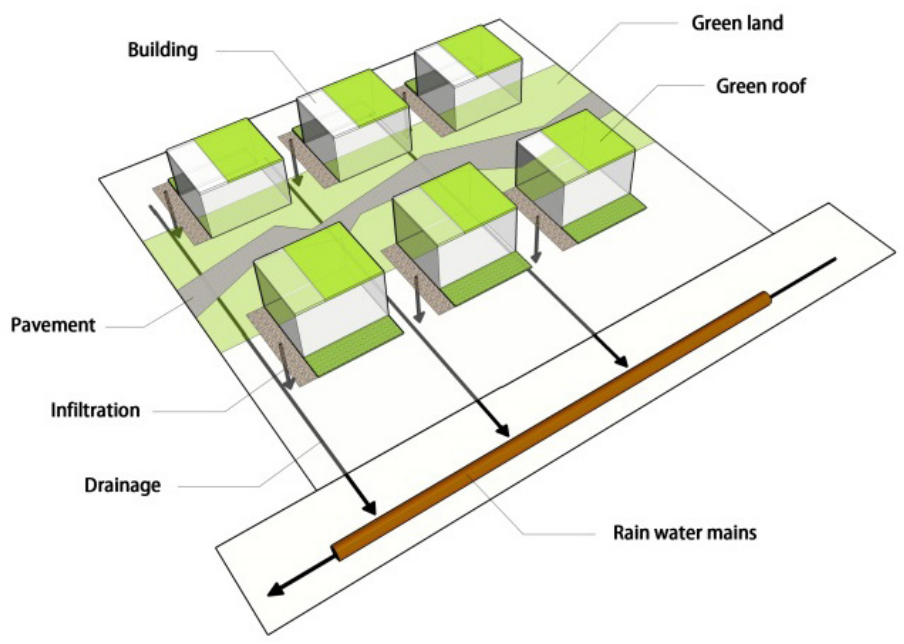

(b)

Figure 4: $\quad$ (a) The planar graph of the storm-water management unit; (b) The diagram of the storm-water management unit.

According to the $\mathrm{Q}_{\text {unit }}$, design rainfall and storm return period, we can work out the integrated flow coefficient --- $\alpha_{\text {unit }}$, which is the integrated control index of SMU. aunit can be ascertained by adjusting the index of the building density, the greening rate, the natural-infiltration-land area rate, the roof-greening rate and infiltration rate of the pavement, so as to achieve the purpose of quantitative management to the storm-water runoff in each SMU. 


\subsubsection{The application of "storm-water management unit"}

The SMU aims at taking the quantitative management to the storm-water runoff, which can be served as planning measures and reference indexes of the transportation planning and the land planning in new city master plan, and finally provide guidance for storm-water quantitative management. As technological means, the theory of SMU will provide technical support for the SMU that beyond emissions targets in built-up area.

\section{Urban storm-water special planning}

\subsection{The principle of the urban storm-water special planning}

The low-impact method of the ecological drain advocated by LID (Low Impact Development) theory is the foundation of the urban storm-water special planning. Combined with storm-water management unit theory, the author put forward to the principle as follows: 1) Keep the natural property in the planning area and consider the natural hydrological process as the basis of the site planning; 2) Keep the hydrological condition and protect the water quality of the surface and ground water; 3) Headstream control to the storm-water and decrease the discharge quantity of the wastewater; 4) Reduce the demand on the drainage system and use a minimal amount of pipeline; 5) Focus on the cyclic utilization of the storm-water and the shaping of the storm-water landscape [2].

\subsection{The content of urban storm-water special planning}

\subsubsection{Environmental carrying capacity assessment in storm-water}

It is necessary to take environmental carrying capacity assessment in storm-water before the planning. The date needed include the condition of the water resources distribution, the local geography, the floodplain and the water sensitive area, the existing municipal infrastructure, the development intensity, the rainfall data and so on. According to the analysis to these data, we can figure out the border of the SQMA and the layout of the drainage point and estimate the maximum stormwater runoff quantity and the heaviest development intensity, which is the foundation to set clear goals.

\subsubsection{Estimate the crest value of the urban storm-water runoff and set the drainage goal}

After figure out the border of the SQMA, we can estimate the crest value $\left(Q_{\text {peak }}\right)$ based on the data of the design storm return period and the SQMA's area, which is the maximum when the site is built up. If we estimate the storm-water runoff maximum (Qbuilt-up peak) of the built-up SQMA, the data of the existing development intensity (including building density, greening rate, the pavement's infiltration capacity) and the design storm return period will be used. The difference between $\mathrm{Q}_{\text {built-up peak }}$ and $\mathrm{Q}_{\text {peak }}$ is what LID IMPs need to cut down, which is also the drainage goal in the built-up SQWA. 


\subsubsection{Divide the "storm-water management unit"}

Combined with the topographic data, the data of the reasonable road span and neighborhood, we can use the $\mathrm{Q}_{\text {peak }}$ to design and lay out the SMUs, which can be the same process as the regulatory planning of the sub-roads during the planning of the new city. There are two different ways if dividing the SMUs in built-up area : Firstly, we can consider the sub- catchment area as big as the neighborhood as a SMU if it can cut down the Qbuilt-up peak according to the adjustment of the storm-water management index; Secondly, we have to redesign the topography or the layout of the pipeline to change the sub-catchment area if not, and the changed sub-catchment area will become a new SMU.

\section{Conclusions}

Urban waterlogging is such a big problem and its complexity let us recognize that it is necessary to use a new method to deal with it. Storm-water management unit theory, as the new methodology, can be considered a new attempt to reorganize the storm-water runoff and cut down them, from which the author put forward to the method of the urban storm-water special planning and hope it can be a more rational way and a quantification method to manage the storm-water.

\section{References}

[1] Xie, Y.X., Development of Drainage Planning in View of Frequent Urban Waterlogging Disasters. Urban Planning, 37(2), pp.45-50, 2013.

[2] Che, W., Ma, Z. and Wang, S. S., et al. Specific Planning for Storm-water Management and Utilization in Chinese Urban Planning System. China Water and Wastewater, 29(2), pp.8-12, 2013. 